Journal of Social Sciences 7 (3): 443-446, 2011

ISSN 1549-3652

(C) 2011 Science Publications

\title{
The Development of Management Models for Local Art Museum in Isan
}

\author{
Santhipharp Khamsa-Ard, Songkoon Chantachan and Marisa Koseyayotin \\ The Research Institute of North Eastern Arts and Culture, \\ Mahasarakham University, Maha Sarakham, 44000, Thailand
}

\begin{abstract}
Problem statement: The development of management in Isan Local Art Museum was necessary for the cultural study. The objectives of this research were: (1) to study the background of management in Local Fine Art Museum, to study the situation and problems of management in Isan Local Fine Art Museum in the present and (3) to develop the model of Isan Local Art Museum. The major purpose was caused by the locality needed to keep the art objects from their ancestors in community. Approach: The research area was Isan Region. The museums in Mahasarakam Province, Kalasin Province and Khon Kaen Province were selected. The samples as informants were 125 persons. The instrument using for collecting data consisted of: The interview form, the observation form, the focus group discussion and participative workshop. Data were investigated by Triangulation. Results: The research findings found that Isan Local Fine Museum had different and various backgrounds in each area. For the development of management in Isan Local Art Museum, the model for community obtaining knowledge in museum management do that every one would be aware of the value, participation in taking care, as well as common usefulness. Conclusion/Recommendations: The museum was indispensable for local community because it was the culture reflecting the advancement and civilization. This research proposed the guidelines in conservation which could be improved by community and related work units, for elevating the value of local museum further.
\end{abstract}

Key words: Local art museum, sustainable system development, knowledge management, local community, exact knowledge

\section{INTRODUCTION}

When there were many local art museums in Isan Locality, the problems of management occurred: the lack of staffs with clear understanding, didn't know correct technique of caring, never perceive the approach or theory to be applied for taking care of those art works correctly. When there were ruined, it was difficult to find something for replacement. Various things, various areas, they were abandoned, dusty, lacked of supervisor, tourists, the study of community, students, lacked of being interested in by the new generation. Almost all caused by the incorrect management, the lack of exact knowledge and understanding in local art, or serious study and wasn't relevant to utility which would occur in future. As a result, there was a lack of correct and appropriate inheritance which was the problem in maintaining for the art and culture of Isan People.
It was difficult for local fine art to avoid the trend of social change according to the age of popularity. So, it needed to study for the guidelines in developing the correct museum management model as well as exist with the changing trend of the world by community participation. Finally, the learning society could be developed. The knowledge was like the very valuable major resource which was different from the other producing factors since it was the changing things which could be changed throughout the time. Therefore, the approach and rationale of Knowledge Management played a major role for every level of organization. The approach and rationale of knowledge management could be applied with the study of management for local art museum. The various bodies of knowledge could be inherited and searched for its origin.

Corresponding Author: Santhipharp Khamsa-ard, The Research Institute of North Eastern Arts and Culture, Mahasarakham University, Maha Sarakham, 44000 Thailand Tel: +66-43-721686 


\section{J. Social Sci., 7 (3): 443-446, 2011}

The Isan Local Art Museum was the thing should be considered for common understanding in correct management and care sp that everything would be existed and inherited to the descendants, with systematic management model, able to be transferred and shared. All of the above was based on participation by community in order to inherit the traditional wisdom not being extinct. Besides, it was the enhancement for local fine art with simplicity and usefulness relevant to social context of community such as the location, weather, material and skill of local artist. All of the above included the maintenance of pattern and existence of art and culture as well as good tradition further so that the cultural heritage would exist with Isan People as long as possible ( Tan, C.N.L., 2011; Seifolddini-Faranak et al., 2009).

\section{MATERIALS AND METHODS}

The area of study, field work data were collected by selecting the area of research as purposive for 5 places as follows: Mahasarakam Province, Mahachai Temple Museum, the management was shown by Banchienghien Remple Museum, the management was shown by public sector, kalasin province, munagfa-sadsongyang museum the management was shown by community, Trairatpittayakom Museum the management was shown by schools and Khon Kaen Province, Chaisri Temple Museum, the management was shown by temple and community, community participation. The samples consisted the experts including the provincial culture, the officers of Provincial Administrative Organization, the officers of Sub-district Administrative Organization, villager wisdom, the museum academic, fine art academic and management academic, total of 35 persons. The practitioner group consisted of the museum manager, the museum supervisor and youth guide in the museum, total of 40 persons. Data were collected by interviewing, observing, focus group discussion and workshop. Data were investigated by using triangulation for being improved and being as a model for the other local art museums.

\section{RESULTS}

The results were as follows:

- The Local Art Museum had various different backgrounds in each area. The objective of establishment was for keeping and maintaining the heritage occurring from wisdom of people in the area. The showed things were ancient from pre- historical age including the pottery and other appliances, historical age including the ogival boundary stone of a temple in Tawarawadee Period, the Buddha Image and book in Lanchang Period, as well as the utensils in the age of constructing houses and country

- Each place of Isan Local Art Museum, had different management conditions and Problems. There were many factors as variables causing the management conditions and problems, in overall, found that: the lack of knowledge in organizing the museum, losing one's capital in taking care of and lacked of staff to take care. As a result, the museum was prosperous and declining alternately

- The management development of Isan Local Art Museum for being existed and inherited from generation to generation without anything to be lost, it needed to develop the model for community in obtaining knowledge for managing the museum so that every one would be aware of the value, participation in taking care. Besides, the related work units could also be able to participate in providing knowledge and developing good understanding in community and management model by participation of community

\section{DISCUSSION}

According to the research findings, could be discussed as follows:

- For historical background and context in developing Isan Local Art Museum they were different in each community area. Most of them collected the art objects and appliances in community to show one's culture. It was a starting point of the identity of local people. It was supported suggested that the participation of community in thinking and decision making, could determine the guidelines in establishing the museum by appointing the working group, including the budget for the establishment and taking care. In addition, the community agreed to set up the local museum. In recent condition, every locality needed to establish one's own museum without interest in body of knowledge required to be included and applied. Moreover, they lacked of knowledge in management of the whole system, although the development and management of Local Art Museum was a technique in showing themselves to the others by different levels of local community that: How the social and cultural growth could lead to the local community strength? And how we could be sustainable live together peacefully as equal status of human beings 


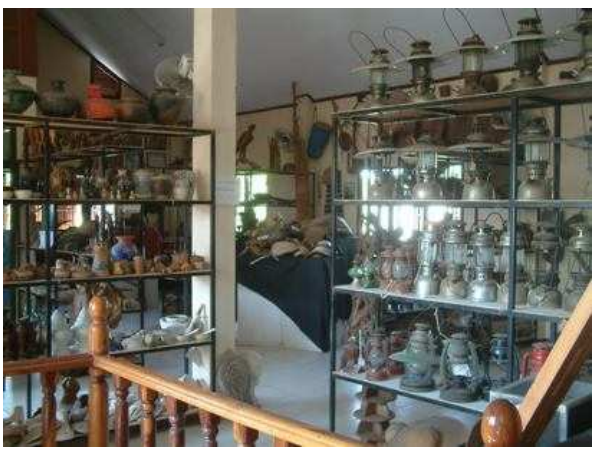

Fig. 1: Photograph thing of Local Art Museum in Isan

- There were various managements of Isan Local Art Museum which depended on context of each area needed to be presented. For the managements, there were many groups of people participating in, from public sector, private sector, community and temple. There were different presentations. Furthermore, different points of presentations were given the importance. Besides, the lack of body of knowledge in exhibition, it wasn't successful as it should be. It was supported studied the local museum, found that it was a type of museum closed with community most. The lo9cal museum often built in the temple from local leader or monk. But, most of them were not successful regarding to the number of visitors. One part of the causes included the unattractive design, inappropriate implementation. People in locality were not interested in participating with the museum. Consequently, the image of Local Museum was only the place for keeping the ancient objects

- The model of management, conservation, rehabilitation for Isan Local Art Museum was obtained for enhancing the cultural value by community participation by determining the local art museum as good model both in the regional, national and international levels, correct management in sustainable system development, attainment of new body of knowledge so that the people in society could have common understanding and participation. So, the art work was a unit of society. It was supported applied the cultural theory in considering the occurrence of local art museum. The congruence would be seen such as the Functionalism Structure Theory which focused on social firmness as the mechanism causing different parts of society to be together and existed according to the time. This theory would emphasize the understanding in the existence and continuity of structure and stability showing the relationship between people with social attachment, or conflict with each other but accepted that conflict with formal conflict management. Such relationship would lower down the opportunity for conflict occurrence and cause the whole society to continue the existence. The occurrence of Isan Local Art Museum was based on the structure and responsibility of society with particular role and function in different social missions especially for society which was not complex (Fig. 1). Therefore, the society could be existed

\section{CONCLUSION}

The participation of community was a factor affecting the existence of local art museum in the Northeastern Region, listening to opinion as well as collaboration in working of different persons such as Sub-district Administrative Organization, teacher team, monk, local wisdom and youth, students etc. It was found that the investment both of physical energy and property from community. Some groups were helped or obtained donated money for such management. When there were agreements in constructing the buildings for showing different objects or things, the community or monks, or the owner of museum, had to collaborate in carrying on so that it could inherit to the youth or new generation for maintaining and developing the understanding in various cultures. For the committee in taking care and management, was one alternative for helping in collaboration in locality. In providing correct knowledge, as well as applying the knowledge for developing the appropriate management model with each place of Isan Local Art Museum, each place should have an opportunity in the study tour as well as performance show in different levels. All of these things, would lead to the inheritance of Isan Region Local Art to be existed as a model for local museum in the other regions or neighborhood countries further.

\section{ACKNOWLEDGEMENT}

The research has been supported generously by the Mahasarakham University Research Fund. The researchers would like to express their sincere appreciation for all of the support provided. 


\section{REFERENCES}

Stein, P.L. and B.M. Rowe, 2002. Physical Anthropology. 8th Edn., McGraw-Hill, Boston, ISBN: 0072485949, pp: 574.

Parkhouse, B.L., 2005. The Management of Sport: Its Foundation and Application, 4th Edn., McGrawHill, New York, ISBN: 0072844124, pp: 388.
Seifolddini-Faranak, M., S. Fard and H. Ali, 2009. Distribution and determining of tourist attractions and modeling of tourist cities for the city of isfahan-iran. Am. J. Econ. Bus. Admin., 1: 160166. DOI: 10.3844/ajebasp.2009.160.166

Tan, C.N.L., 2011. Knowledge management acceptance: success factors amongst small and medium-size enterprises. Am. J. Econ. Bus. Admin., $\quad 3: \quad 73-80 . \quad$ DOI: 10.3844/ajebasp.2011.73.80 